\title{
Guideline for Backfill Material Improvement for Water Supply Pipeline Construction on Bangkok Clay, Thailand
}

\author{
Sideth Prum ${ }^{1}$, Nalinee Jumnongpol ${ }^{2}$, Chutima Eamchotchawalit ${ }^{3}$, Pisit Kantiwattanakul, \\ Vannee Sooksatra $^{4}$, Thanatip Jarearnsiri ${ }^{5}$, and Somsak Passananon ${ }^{2}$ \\ ${ }^{1}$ Suvannaphum Investment Co., Ltd \\ Sangkat Boeng Kak II, Phnom Penh, Cambodia \\ sidethprum@gmail.com \\ ${ }^{2}$ Metropolitan Waterworks Authority \\ 400 Prachachuen Road, Laksi, Bangkok, Thailand \\ nalinee.j@mwa.co.th; somsak_pas@yahoo.com \\ ${ }^{3}$ Thailand Institute of Scientific and Technological Research \\ 35 Mu 3 Technopolis, Khlong Ha, Khlong Luang, Pathum Thani, Thailand \\ chutima@tistr.or.th \\ ${ }^{4}$ Civil Engineering Department, College of Engineering, Rangsit University \\ drpisitk@yahoo.com; vannee@rsu.ac.th \\ ${ }^{5}$ Suphan Buri, Rural Road Office, Bureau of Rural Roads 18 (Suphan Buri), Thailand \\ thanatip_na@hotmail.com
}

\begin{abstract}
Bangkok clay is a well-known soft clay among engineers around the world who work with soil-related fields. Many government institutions have to deal with many pipeline construction problems and open-cut trench technique due to many of its responsible regions containing Bangkok soft clay. The aim of this paper is to review the soil improvement techniques used in the construction of water supply pipelines and open-cut trench technique for solving pipeline construction \& maintenance problems in responsible areas. Based on the related data, pipeline construction standards, backfill materials and zoning of construction, techniques have to be considered for improvement, and the effect of Bangkok clays must be considered in proposing suitable soil improvement techniques. In order to solve the problem, factors such as the ability for working on site with simplified components and techniques, efficient quality control, local and low cost material must be considered for the application of soil improvement. Due to the fact that the technique must be applicable to solve the problems, three soil improvement techniques were presented including: 1) Liquefied Stabilized Soil (LSS) technique 2) Controlled Low Strength Material (CLSM) technique and 3) Soil improvement with liquefied rubber technique. These techniques are appropriate for various conditions of the regions such as area constraint, constructions time, and material availability. Several materials can be applied for the two prominent techniques (LSS and CLSM). Those materials are excavated soil, reused or by-product materials, etc. On the other hand, using liquefied rubber for soil improvement requires short duration for hardening and construction. The essential composition of "Liquefied Rubber" is a natural product, which can be found locally. These are the dominant factors of this technique. Hence, the natural rubber value is added to rubber products industry in South East Asia region. This technique enhances the sustainable development of a Green Material in the future.
\end{abstract}

Keywords: Backfill material, Soil improvement, Bangkok Clay, Water supply pipeline construction.

\section{Introduction}

Metropolitan Waterworks Authority (MWA), Provincial Waterwork Authority (PWA), Department of Public Works and Town \& Country Planning (DPT) and other government institutions have responsible areas that are located in the Lower Central Plain of Thailand called the Chao Phraya Basin. It lies on Bangkok clay which is the uppermost soil layer and can be found extensively in the Lower Central Plain of Thailand. Bangkok clay consists of soft greenish gray clay with abundant shell fragments that was deposited in a shallow marine environment [1]. The characteristics of Bangkok clay are low strength, high compressibility, low sensitivity, high water content and plasticity index [2].

Therefore, construction projects experience problems related to this soil layer "Bangkok Clay" that geotechnical engineers and the industry have to face and resolve. 
A lot of techniques and solutions have been studied in order to solve the construction problems due to Bangkok Clay or Marine Clay. The main problems for geotechnical engineering are physical and mechanical properties such as strength and high water content that can cause structures to settle.

Two PWA Regional Office are responsible for the construction of pipelines of 9 provinces where there are construction problems due to Bangkok Clay whereas MWA is responsible for Bangkok area, Nonthaburi and Samut Prakarn. MWA water supply capacity is 6.2 million cubic meters per day to serve more than 10 million people in the vital economic centre of the country. The service area of MWA is 2,449.27 square kilometres including the capital city of Bangkok, as well as Samut Prakan and Nonthaburi. MWA's responsible area covers an equivalent pipeline distribution length of 37,700 kms.

This responsible area in the Chao Phraya delta also experiences flooding every year because some areas are lower than the mean sea level. Nowadays, global climate change has a significant impact in exacerbating urban flooding, and this is extended to Thailand. The urban area of Sukumvit experienced such a significant flooding event in May 2017 [3]. Flooding is one of the most important contributing factors to causing construction problems. Some responsible areas are close to the gulf of Thailand. Therefore, the tidal effects are also considered for the construction plan and repair projects. The pipeline failures occur on distribution pipelines from different types of materials, but mainly PVC, AC, ST, GI, HDPE and CI. However, most pipeline failures occur in PVC pipelines which account for almost 28,400 kilometres of the total network, and it is the dominant part of MWA's water loss every year.

The causes of pipeline problems can be divided into 2 factors: internal factor and external factor. The internal factors are types of material, pressure system and pipeline lifetime which related institutions can manage or control in management process. The important factors that contribute significantly for pipeline failures are external forces including pipeline displacement and different settlement of substructures. These external factors are related to the soil underneath the pipeline namely Bangkok clay or marine clay.

Sand is commonly used to protect buried utilities and water supply pipelines. Government institution also uses sand as backfilling material. Sand is used as bedding and filling materials in pipeline trench in order to decrease the external forces exerting on pipelines. In the case of loss of bedding and filling materials from a pipeline trench, the external forces would directly transfer to the pipeline structures and cause breaking of pipelines due to differential settlement and displacement. Predominant factors for the loss of bedding and filling materials in MWA's trench are tidal effect and flooding because those areas lie on Bangkok clay.

The questions are "How can MWA, PWA and other institutions protect the bedding and filling materials in the trench? How would the sand cohesion be improved against the tidal effect or flooding? What kind of materials are appropriate for the affected areas? What are the specific techniques for repairing?" These questions are challenges for them since all of these factors have significant effects on the leakage and water loss, and benefit to them. Decreasing or eliminating them will drive MWA and PWA towards being a higher-performance water supply organization and reach international standards in the future.

This paper aims to review the soil improvement techniques for use in the construction of water supply pipelines together with record data for solving the pipeline construction \& repairing problems in responsible area. Based on the related data; pipeline construction standards, backfill materials and zoning of construction techniques have to be considered for improvement.

\section{The study of area conditions}

Metropolitan Waterworks Authority (MW), Provincial Waterworks Authority (PWA), Department of Public Works and Town \& Country Planning (DPT) and other government institutions are situated on the flood plain and delta of the Chao Phraya River. Bangkok clay is one of the well-known sedimentary soils. Many researchers have studied it extensively both in academic institutes as well as government departments for understanding the boundary, properties, and behaviors of this soil. The soil models were also studied to investigate the Bangkok clay behaviors. [4]

Various soil data sources show the complicated studies of researchers. Many researchers in different institutions, including the Department of Mineral Resources and Department of Public Works and Town \& Country Planning (DPT) collaborated to investigate and collect the important data such as boundary and depth of Bangkok clay, physical and mechanical properties, etc. into a database system.

Geotechnical engineering properties of Bangkok clay can be divided into two categories: Bangkok clay or marine clay and stiff clay, as shown in Table 1. Bangkok clay boundary (Fig.1) is defined by marine clay characteristics [3]. Two characteristics of clay layer also show the relationship of three indexes namely natural water content, total unit weight and 
unconfined compressive strength by depth of Bangkok clay (Fig.2). According to Fig.2 a) and c), as all pipeline construction is typically performed in the top soil layer, they are typically subject to high water content and low compressive strength.

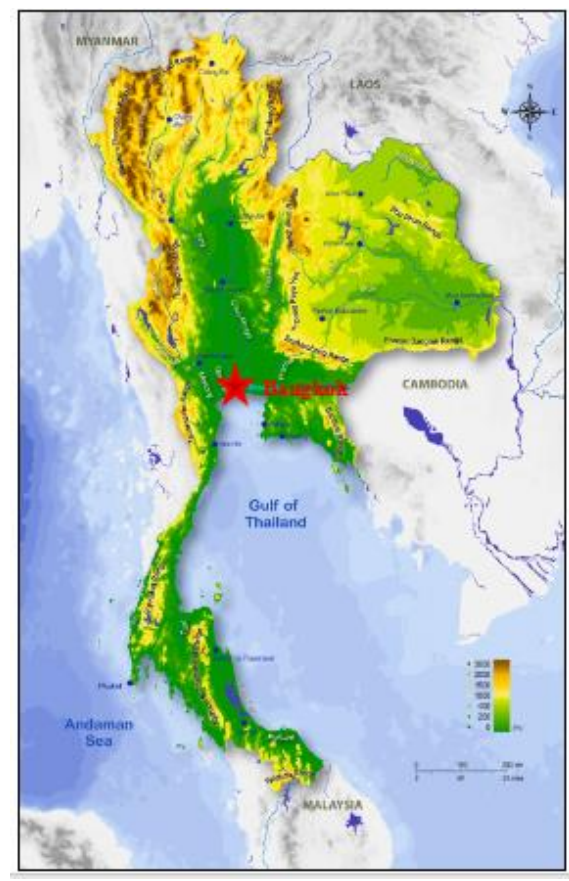

a) Location of Bangkok.

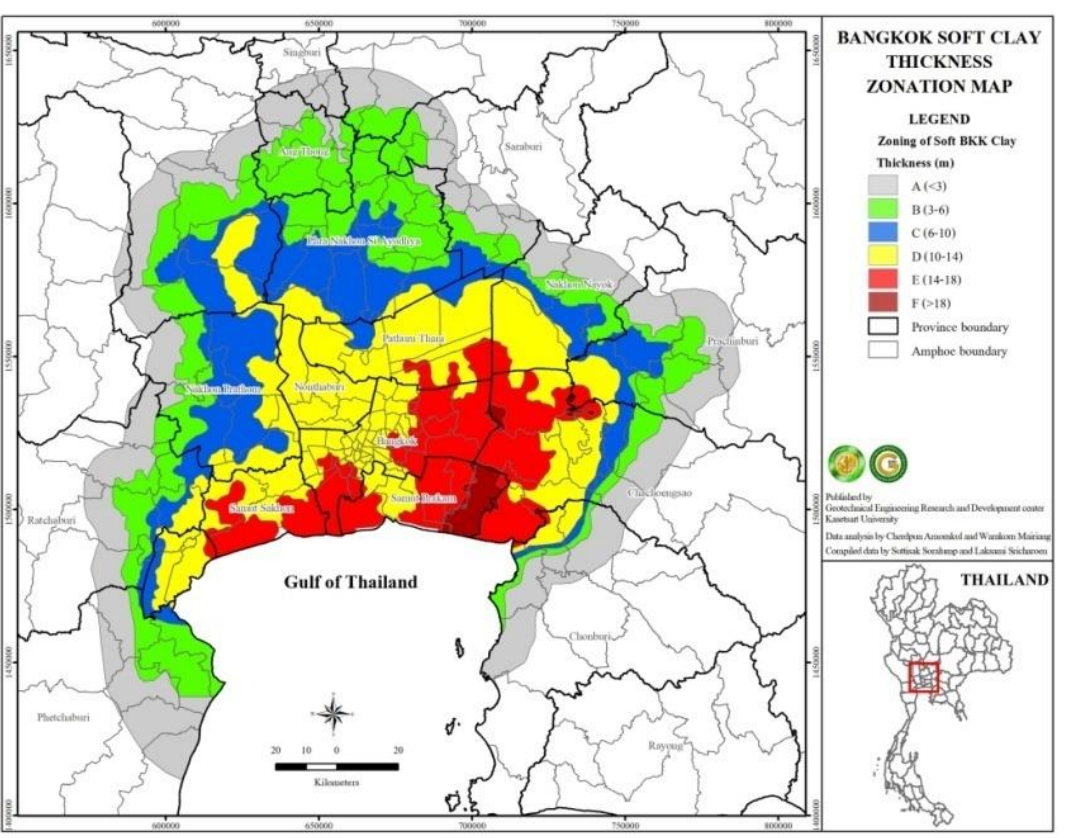

(b) Zone of Bangkok Soft Clay Thickness.

Fig. 1: Geology map of Thailand.

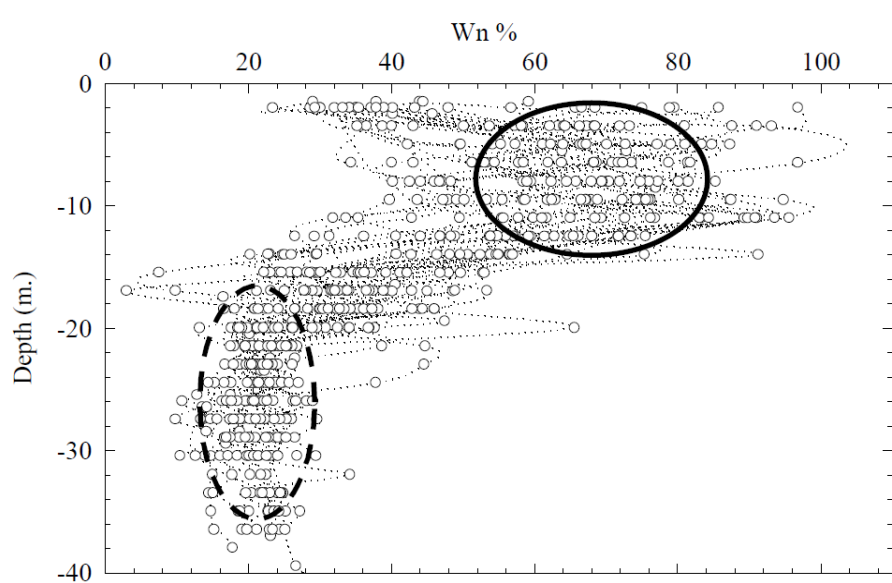

a) Natural water content versus depth of Bangkok.

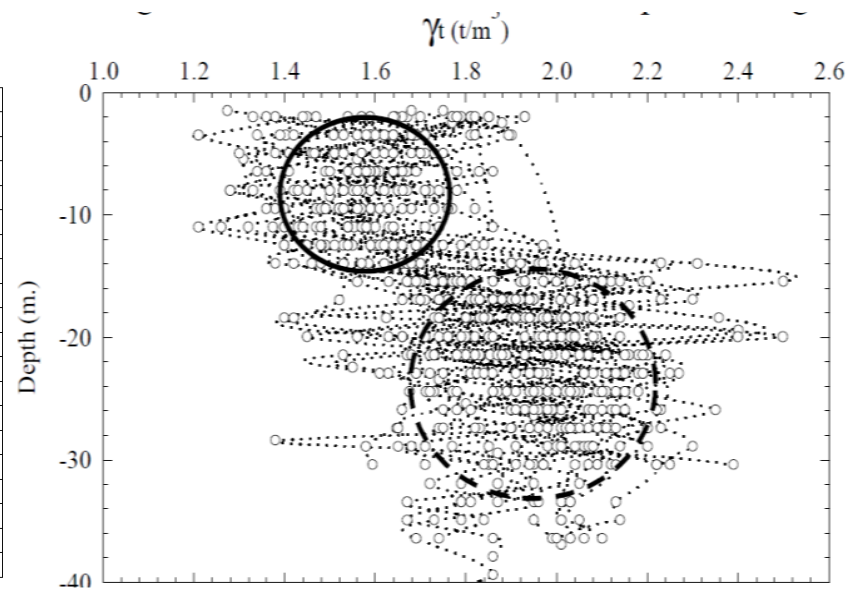

b) Total unit weight versus depth of Bangkok. 


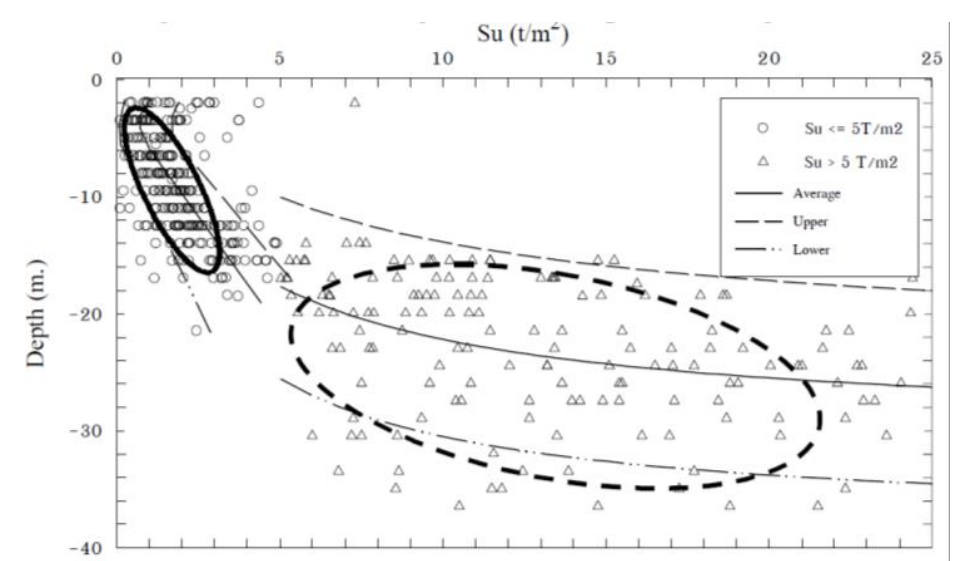

c) Unconfined compressive strength versus depth of Bangkok subsoil.

Fig. 2: The relationships between natural water content, total unit weight and unconfined compressive strength versus depth [2].

Table 1: Soil properties in the Lower Central Plain [2].

\begin{tabular}{|l|c|c|}
\hline \multicolumn{1}{|c|}{ Properties Index } & Bangkok Clay & Stiff Clay \\
\hline Natural Water Content & $\approx 40-90$ & $\approx 15-30$ \\
\hline Liquid limit & $\approx 30-60$ & $\approx 30-55$ \\
\hline Plastic limit & $\approx 15-30$ & $\approx 15-25$ \\
\hline Plasticity Index & $\approx 0-4$ & $\approx 0.5-1.0$ \\
\hline Total unit weight & $\approx 1.4-1.6 \mathrm{t} / \mathrm{m}^{3}$ & $\approx 1.8-2.2 \mathrm{t} / \mathrm{m}^{3}$ \\
\hline Unconfined Compressive Strength & Mostly less than $5 \mathrm{t} / \mathrm{m}^{3}$ & Mostly more than $5 \mathrm{t} / \mathrm{m}^{3}$ \\
\hline
\end{tabular}

\section{Hypothesis and Methodology}

\subsection{Hypothesis}

According to field data and interview data, the surrounding area of pipeline failure shows the characteristics of trench status, failure type, infrastructure or substructure is close to the pipe due to the loss of bedding \& filling materials. These characteristics were investigated by site project engineers, workers and personnel on site. More than 80 percent of failure data shows that the loss of bedding and filling material is an important cause.

Based on the collected data, the hypothesis is set for solving pipeline failure problems as follows:

- The properties of bedding and filling material consist of low cohesion and flexibility.

- The tidal effect and flooding have significant effect on trench characteristic including bedding and filling materials.

- MWA responsible area is related to areas affected by the Bangkok clay boundary and its engineering properties.

\subsection{Case study of pipeline construction problems}

Generally, the locations of distribution pipelines are classified into three cases: 1) under the street 2) at the right of way of the street and 3) in subgrade soil. According to the data, from highest to lowest, most of failure problems are classified by failure in the subgrade soil, then under the street and followed by in the right of way. Failures have been caused by external forces from surroundings more than pressure systems and materials factor. The efficiency of bedding and filling material is important for decreasing the load transferred to pipeline structure.

This paper aims to study and analyze the problems of pipeline distribution system. The case studies are PVC class 8.5 and class 13.5 with diameters of $100-400 \mathrm{~mm}$. The construction method is open-cut trench construction, as shown in Table 2 and Fig.3-4 


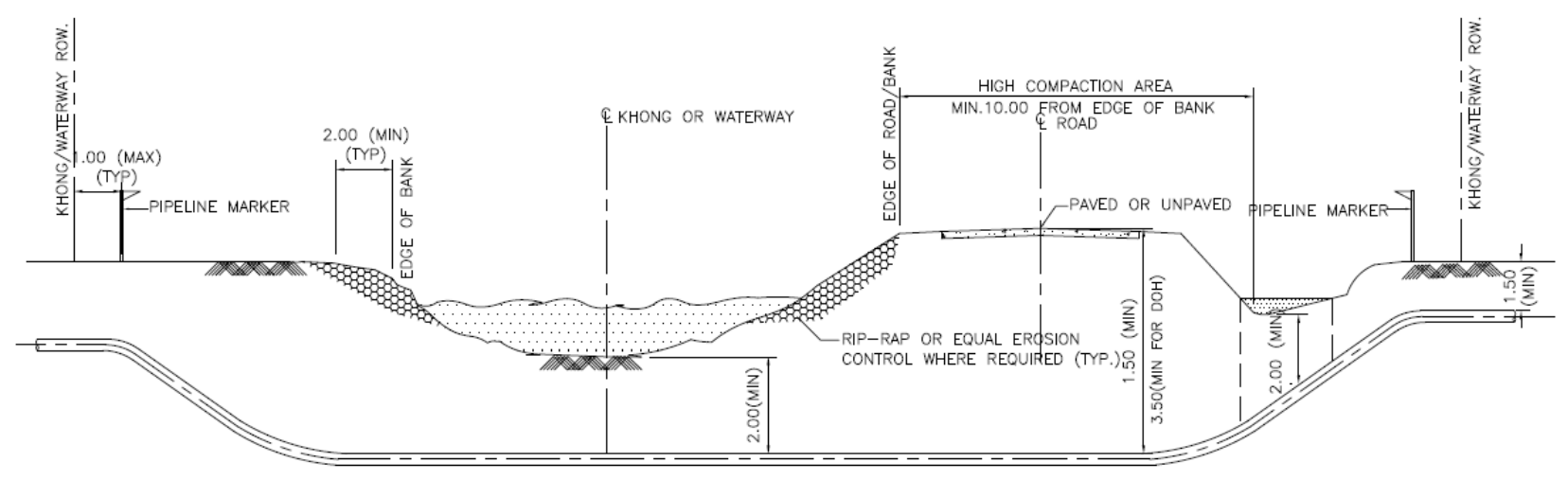

Fig. 3: General typical road and waterway crossing.

Table 2: MWA's standard of pipeline construction for PVC Class 8.5/ Class 13.5 by open-cut trench method.

\begin{tabular}{|c|c|c|c|c|c|}
\hline \multirow{2}{*}{$\begin{array}{c}\text { Pipe Dia. } \\
\text { (mm.) }\end{array}$} & \multicolumn{2}{|c|}{ Depth (m) } & \multicolumn{3}{c|}{ Dimension of pipe lining (m) } \\
\cline { 2 - 6 } & PVC class 8.5 & PVC class 13.5 & b & w & S \\
\hline 100 & 0.60 & 0.40 & 0.15 & 0.50 & $\approx 0.190$ \\
\hline 150 & 0.60 & 0.45 & 0.15 & 0.50 & $\approx 0.167$ \\
\hline 200 & 0.80 & 0.60 & 0.15 & 0.55 & $\approx 0.167$ \\
\hline 300 & 0.80 & 0.60 & 0.15 & 0.65 & $\approx 0.166$ \\
\hline 400 & 0.80 & 0.60 & 0.15 & 0.80 & $\approx 0.190$ \\
\hline
\end{tabular}

\subsection{Suggestions on soil improvement technique}

The soil improvement technique for solving the problems must take into account the following conditions:

- The method can be applied in real construction site.

- The method is not complicated and available for soil improvement in a short timeframe and allows for efficient quality control.

- The properties of admixture should be general, simplified components, using local and low cost materials.

These conditions will support the hypothesis for solving the problems.

Since institutions found that most problems are related to bedding and filling materials, those institutions have improved the standard of construction method and bedding material as shown in note of Fig.4. In case of the depth of sand bedding is less than $0.15 \mathrm{~m}$, MWA specifies the use of the Controlled Low Strength Material (CLSM). If the strength is less than 0.5 $\mathrm{MPa}, \mathrm{MWA}$ has to determine to improve the construction standard with new bedding and filling material. However, CLSM is not available to be used on the site because of the constraint of site location, proportion and cost. Because the current CLSM is typically a ready mix rather than soil cement which is a low strength material with the use of nearby soil, most contractors would need to use a concrete plant manufacturer for supply. The factors of time and transportation must be considered to manage the quality control.

According to the collected data and previous research, the soil improvement techniques involving in changing soil characteristics by a chemical reaction is considered together with construction factor. The process such as using admixture, including or mixing the soil by binder material or higher efficiency materials are appropriate for their problems. The focused soil improvement techniques include:

- Liquefied Stabilized Soil (LSS) technique

- Controlled Low Strength Material (CLSM) technique

- Soil improvement with liquefied rubber technique 


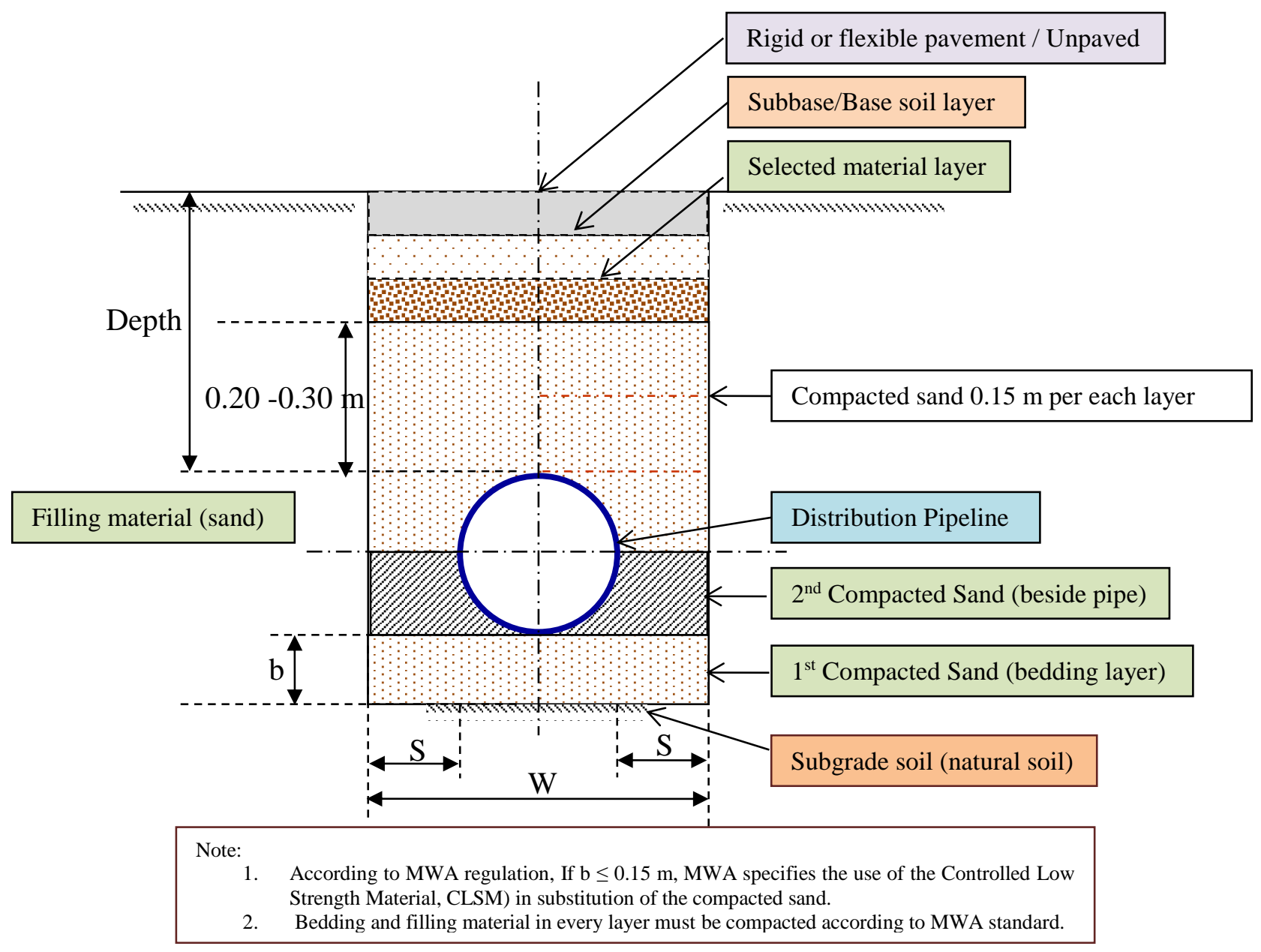

Fig. 4: MWA's typical pipeline cross-section by open-cut trench method.

Liquefied Stabilized Soil (LSS) technique is the one of the effective methods of using the excavated soil from the construction works [5]. LSS is the technique which add the chemical materials to be a binder for the physical properties improvement. It is used for increasing of the soil cohesion between soil particles such as muddy material, and is stabilized with cement material. The LSS is made by excavated soil from construction site, which is inhomogeneous soil, while generally slurry is made from the homogeneous soil material. The characteristic of LSS is explained in terms of the parameters such as flow, strength, density, and bleeding ratio. The proportions of LSS depend on the purpose and work of the construction site including raw materials too. Japanese researchers have done the experiment of LSS properties. LSS should have the following characteristics [6]:

1. Easy to re-excavate

2. Minimal shrinkage in the ground

3. Minimal corrosion by running water in the ground

4. Almost in-permeable

5. Liquefaction free in earthquake

6. No $\mathrm{pH}$ rising around the ground

7. Use of slurry waste

Because LSS characteristics is slurry from mixing cement with excavated soil with high water content; by-product or reuse materials will be appropriate for LSS mixing. There is therefore the reason for the guideline of MWA sludge application to be applied for the filling materials with LSS method in the future.

There has been a lot of research which has studied the soil improvement by using cement-stabilization for the strength development of clay [7] or Bangkok clay [8]. The LSS method is well known for soil improving technique, which has the 
ability to improve the cohesiveness of soil into slurry, by increasing water content [9]. This material does not need to be compacted as normal soil but can be used to fill narrow space such as trench or ditch due to the flow ability. When LSS becomes hard, the strength will be developed as the concrete is placed in a form.

Controlled Low Strength Material (CLSM) technique is a well-known backfill material used for earthworks since the 1985 ACI Committee 229 set up a comprehensive report for covering the applications and other topic of CLSM for implementing in engineering fields. The ACI Committee 229 report was published in 1994 and used on April 29, 1999. For more than 30 years, CLSM has been applied in engineering constructions such as substructure utilities, infrastructure, filling trench, pipeline construction for bedding and filling materials. The application of CLSM has still been continuously developed for new materials, new technology and new construction technology. So there are many publications being published every year. An overview of CLSM publishing has been collected, classified and summarised. It shows that 115 publications have published from 20 countries from 1990-2017. The overview papers show the CLSM application in North America, United Kingdom, Australia and Asia. Those applications are classified by function as bedding material, utility of trench [10,11], recycled excavated material, void filling, bridge approaches, backfilling, grouting material for pavement, etc. [12]

The technique of CLSM is designed for high flowability ( $>200 \mathrm{~mm}$ spread) and low compressive strength $\leq 2.1 \mathrm{MPa}$ including the one of self-compacting which has cementitious material. These are the reasons to support the using of CLSM worldwide, recently. The advantages of CSLM and LSS is the variety of the materials that can be used such as reused material and slurry waste from manufacturing processes, and by-product materials [13], water treatment sludge, excavated soil, etc. Therefore, the CLSM can be called a sustainable "Green Material" since main materials are from non-toxic waste or reused materials. This method will support the added value for by-product as well.

Soil improvement with liquefied rubber technique has been used in the South East Asia zone where there are different types of rubber products. This technique has been applied for highway material and embankments such as subbase, base, and embankments including flexible pavement. The dominant properties of rubber product is its flexibility and tensile strength. Liquefied rubber can increase the shear strength and dilatancy because the cohesiveness of soil has been improved by rubber properties. The soil will be more elastic and flexible than its original state. The improved soil will be more effective to be used as bedding and backfill materials, which provide less crack and failure. The mechanisms for increasing shear strength are the increasing of dilatancy, the effective force and cohesion [14]. Duration for construction and setting time is less than other methods described above. Table 3 shows details of three soil improvement techniques.

Table 3: Soil improvement techniques for determining.

\begin{tabular}{|c|c|c|c|c|c|c|c|}
\hline Method & Main Material & Binder & $\begin{array}{l}\text { Water } \\
\text { content }\end{array}$ & Filler material & Flowablity & Compaction & $\begin{array}{l}\text { Hardening } \\
\text { time }\end{array}$ \\
\hline LSS & $\begin{array}{l}\text { Any soil, excavated soil, } \\
\text { sludge, waste, reuse } \\
\text { material, by-product etc. }\end{array}$ & Cement & High & $\begin{array}{l}\text { Fly Ash, } \\
\text { Bottom Ash, } \\
\text { waste, by- } \\
\text { product etc. }\end{array}$ & $\begin{array}{l}\text { High, } \\
\text { Medium, } \\
\text { Low }\end{array}$ & Not required & $\begin{array}{l}\text { Can be as } \\
\text { short time as } \\
\text { 1hr, generally } \\
3-5 \text { hr under } \\
\text { normally } \\
\text { condition }\end{array}$ \\
\hline CLSM & $\begin{array}{l}\text { Any soil, re-excavated } \\
\text { soil, sludge, waste, reuse } \\
\text { material, by-product etc. }\end{array}$ & Cement & High & $\begin{array}{l}\text { Fly Ash, } \\
\text { Bottom Ash, } \\
\text { waste, by- } \\
\text { product etc. }\end{array}$ & $\begin{array}{l}\text { High, } \\
\text { Medium, } \\
\text { Low }\end{array}$ & Not required & $\begin{array}{l}\text { Can be as } \\
\text { short time as } \\
1 \mathrm{hr} \text {, generally } \\
3-5 \text { hr under } \\
\text { normally } \\
\text { condition }\end{array}$ \\
\hline $\begin{array}{l}\text { Liquefied } \\
\text { Rubber }\end{array}$ & $\begin{array}{l}\text { Sand, silty clay, silty } \\
\text { clay }\end{array}$ & $\begin{array}{l}\text { Liquefied } \\
\text { Rubber }\end{array}$ & $\begin{array}{c}\text { Low, } \\
\text { depend on } \\
\text { main } \\
\text { material }\end{array}$ & - & Low & Required & $\begin{array}{l}\text { Can be as } \\
\text { short time as } \\
15 \text { min, } \\
\text { generally } 30 \\
\text { min to } 1 \text { hrs. }\end{array}$ \\
\hline
\end{tabular}




\section{Conclusion}

These three techniques were proposed for solving the problems arising due to construction problems on site. The implementation for MWA responsible area shall be considered with subgrade soil properties on site for highest advantage.

The areas which are affected by tidal times can limit allowable construction time to within just 2-3 hours before the trench will be submerged under the water, and as such, should be considered for implementing the liquefied rubber soil improvement technique.

Further research shall be performed with more experiments on physical properties of local materials in the their regions as well as how MWA water treatment sludge is to be applied for LSS, CLSM technique. The extended research for applying the techniques in fields shall also be considered.

\section{Acknowledgements}

The authors would like to thank Thailand Institute of Scientific and Technological Research (TISTR), Suphan Buri Rural Road Office for their support.

\section{References}

[1] C. Sinsakul, "Late Quaternary geology of the Lower Central Plain, Thailand," J. of Asian Earth Sciences, vol. 18, pp. 415-426, 2000.

[2] N. Teerachaikulpanich and V. Phupat, "Geological and Geotechnical Engineering Properties of Bangkok Clay," in Proceedings of the 38th International Conference on Geotechnical Engineering, Japan, 2003, pp. 143-144.

[3] S. Wongsa, V. Vichiensan, N.Piamsa-nga and S. Nakamura, "Urban Flooding and Adaption to Climate Change in Sukhumvit Area, Bangkok, Thailand," in Proceedings of International Conference on Urban Drainage Modelling, Palermo, Italy, 2018, pp. 644-648.

[4] C. Surarak, S. Likitlersuang, D. Wanatowski, A. Balasubramaniam, E. oh and H. Guan, "Stiffness and strength parameters for hardening soil model of soft and stiff Bangkok clays," J. of Soil and Foundations, vol. 52, no. 4, pp. 682697, 2012.

[5] Kuno, Goro, eds, "Liquefied Stabilized Soil Method-Recycling technology of construction-generated soil and mud," Gihodo Publication, Japan, 1997.

[6] Kuno, Goro, V. Vichiensan, N. Piamsa-nga and S. Nakamura, "Recycling Excavated Soil to Back-Filling Material with Liquefied Stabilized Soil Method," in Proceedings CIB World Building Congress, Gaevle, Sweden, 1998.

[7] S. Horpibulsuk, R. Rachan, A. Chinkulkijniwat, Y. Raksachon, and A. Suddepong, "Analysis of strength development in cement-stabilized silty clay from microstructural considerations," J. of Construction and Building Materials, vol. 24, pp. 2011-2021, 2010.

[8] K. Uddin, A. S. Balasubramaniam, and D. T. Bergado, "Engineering Behaviour of cement treated Bangkok soft clay," J. of Geotechnical Engineering, vol. 28, pp. 89-119, 1997.

[9] H. Miki., J. Iwabuchi and S. Chida, New soil treatment in Japan, Japan, 2005.

[10] A. Blanco, P. Pujadas, S. H. P Cavalaro, A. Aguado, "Methodology for the design of controlled low-strength material. Application to backfill of narrow trench," J. of Construction and Building Materials, vol. 72, pp. 23-30, 2014.

[11] H. Li-Jeng, W. Her-Yung, S. Yeong-Nain and L. Duc-Hien, "Earth Pressure and Settlement Analysis of Trench Ducts Backfilled with Controlled Low Strength Materials," in Procedia Engineering of Sustainable Development of Civil, Urban and Transportation Engineering Conference, vol. 142, pp. 174-181, 2016.

[12 T. C. Ling, S. K. Kaliyavaradhan, C. S. Poon, "Global perspective on application of controlled low-strength material (CLSM) for trench backfilling-An overview," J. of Construction and Building Materials, vol. 158, pp. 535-548, 2018.

[13] Y. S. Kim, T. M. Do, M. J. Kim, B. J. Kim and H. K. Kim, "Utilization of by-product in controlled low-strength material for geothermal systems: Engineering performance, environmental impact, and cost analysis," J. of Cleaner Production, vol. 172, pp. 909-920, 2018.

[14] W. Kokkamheang, P. Kantiwattanakul, "Behavior of Soil Stabilize by Liquefied Rubber,” M.Eng. thesis, Dept. Civil. Eng., Rangsit Univ., Prathum Thani, Thailand. 